\title{
Strong negative correlation between dust event frequency and air temperature over the northern Tibetan Plateau reflected by the Malan ice-core record
}

\author{
Ninglian WANG, ${ }^{1,2}$ Tandong $\mathrm{YAO}^{2}{ }^{2}$ L.G. THOMPSON, ${ }^{3}$ M.E. DAVIS ${ }^{3}$ \\ ${ }^{1}$ Key Laboratory of Cryosphere and Environment, Cold and Arid Regions Environmental and Engineering Research Institute, \\ Chinese Academy of Sciences, 260 Donggang West Road, Lanzhou 730000, China \\ E-mail: nlwang@|zb.ac.cn \\ ${ }^{2}$ Institute of Tibetan Plateau Research, Chinese Academy of Sciences, 18 Shuangqing Road, Haidian District, \\ Beijing 100085, China \\ ${ }^{3}$ Byrd Polar Research Center, The Ohio State University, 1090 Carmack Road, Columbus, OH 43210-1002, USA
}

\begin{abstract}
In this paper, the ratio of dust layer thickness to ice thickness, i.e. the dust ratio, is used as a proxy for dust event frequency in the Malan ice core from the northern Tibetan Plateau. We reconstructed a $\sim 900$ year record that reveals that the $1770 \mathrm{~s}-1880 \mathrm{~s}$ was a prolonged period of high dust ratios, which indicates that dust events occurred frequently from the late 18th century through the 19th century. Statistical analysis of the variations in the dust ratios and $\delta^{18} \mathrm{O}$ (which is a good proxy for air temperature) in the Malan ice core shows that there is a strong negative correlation between them. This suggests that dust events occur more frequently in cold periods than in warm periods.
\end{abstract}

\section{INTRODUCTION}

Atmospheric dust plays a very important role in the Earth's climate system. It affects both the solar and terrestrial radiation by scattering and absorption, modifies cloud properties and the hydrological cycle, and influences tropospheric photochemistry (Andreae, 1996; Ramanathan and others, 2001; Kaufman and others, 2002; Prospero and Lamb, 2003). Dust supplies to the ocean could have fertilized the biota and driven atmospheric $\mathrm{CO}_{2}$ lower (Martin and others, 1994; Watson and others, 2000; Ridgwell, 2002). Thus, atmospheric dust is considered to be a significant climate-forcing factor. Atmospheric dust loading is related to terrestrial dust emissions. Dust storm frequency is a surrogate for dust emissions, and is very high in desert/deflated regions (Engelstaedter and others, 2003). The world's major dust sources include North Africa, the Arabian Peninsula, central Asia and Australia. Reconstructions of the histories of dust storm frequencies in different regions, especially in the major dust source areas, can help us to understand the past variations in atmospheric dust loading and dust-climate interactions. Visible dust layers are usually formed on glaciers close to the source areas during the seasons in which dust events (including dust storms, blowing sand and floating dust) are most frequent. Ice cores from central Asia provide a unique way to reconstruct dust event frequencies (DEFs) in this region. In this paper, we will report the results of the reconstruction of DEF, and investigate the correlation between DEF and temperature, based on the record of the Malan ice core from the northern Tibetan Plateau.

\section{MEASUREMENT METHODOLOGY}

The Malan ice cap $\left(35^{\circ} 50^{\prime} \mathrm{N}, 90^{\circ} 40^{\prime} \mathrm{E}\right)$, with an area of $195 \mathrm{~km}^{2}$ and a summit elevation of $6056 \mathrm{~m}$, is located in the Kunlun Shan on the northern Tibetan Plateau (Fig. 1). Its
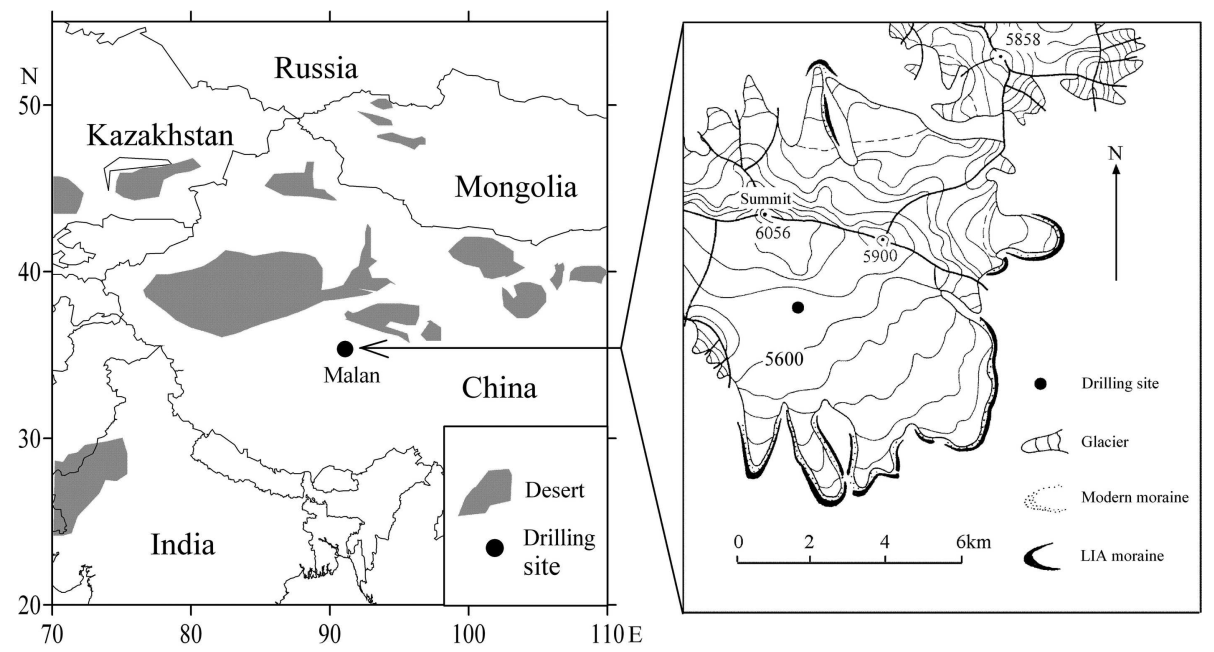

Fig. 1. Location of the Malan ice-core site and distributions of deserts in central Asia. Spot elevations and contours in the right panel in ma.s.I. (contour interval 100 m). LIA: Little Ice Age. 

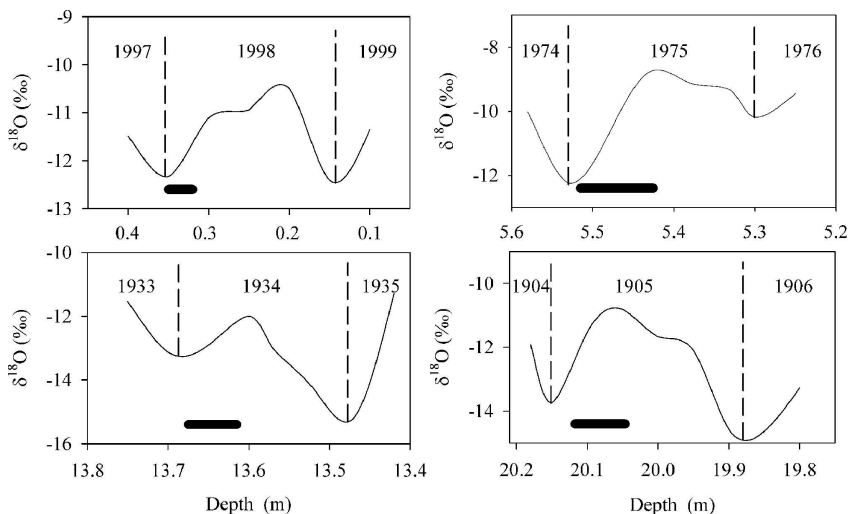

Fig. 2. The positions of the yellow dust layers (black bars) and the seasonal variations in $\delta^{18} \mathrm{O}$ (solid curves) at different depths in the Malan ice core. High values of $\delta^{18} \mathrm{O}$ represent summer, and low values represent winter. The years of ice at different depths are also displayed.

lowest elevations are $\sim 5000 \mathrm{~m}$ on the north side, where the snowline varies between 5340 and $5440 \mathrm{~m}$ a.s.l., and $5120 \mathrm{~m}$ on the south side, where the snowline varies between 5500 and 5540 ma.s.l. In 1999, a $102 \mathrm{~m}$ ice core was drilled at $5680 \mathrm{~m}$ a.s.l., where the $10 \mathrm{~m}$ borehole temperature was about $-6.5^{\circ} \mathrm{C}$. The core was returned frozen to the Key Laboratory of Cryosphere and Environment of the Chinese Academy of Sciences, where $\delta^{18} \mathrm{O}$ was measured by gas stable-isotope-ratio mass spectrometry (MAT-252). The timescale was established using seasonal variations in $\delta^{18} \mathrm{O}$ for the upper part of this core $(\mathrm{N}$. Wang and others, 2003a, b) and a Nye model for the lower part (Wang and others, in press). A nearly 900 year record of climatic and environmental changes can be reconstructed based on the Malan ice core (Wang and others, in press).

Most studies have shown that southern Xinjiang, where the Taklimakan desert is located, is an area that experiences frequent dust events (Zhou, 2001; S. Wang and others, 2003). Considering that both southern Xingjiang and the northern Tibetan Plateau are dominated by westerlies, the Malan ice core is situated on the leeward side of this area of frequent dust-movement activity (see Fig. 1). This implies

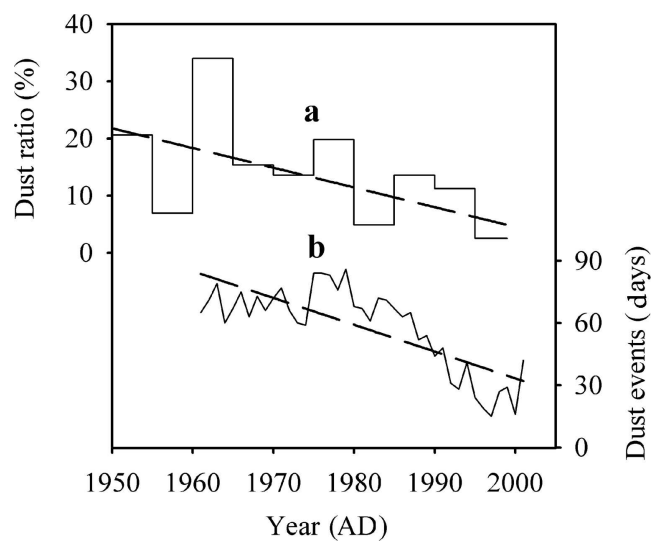

Fig. 3. Comparison between the variations in dust ratio ( 5 year mean) in the Malan ice core (a) and frequency of dust events (including dust storms, blowing sand and floating dust) that occurred in spring in southern Xinjiang (b) in the past 50 years (He and others, 2003).

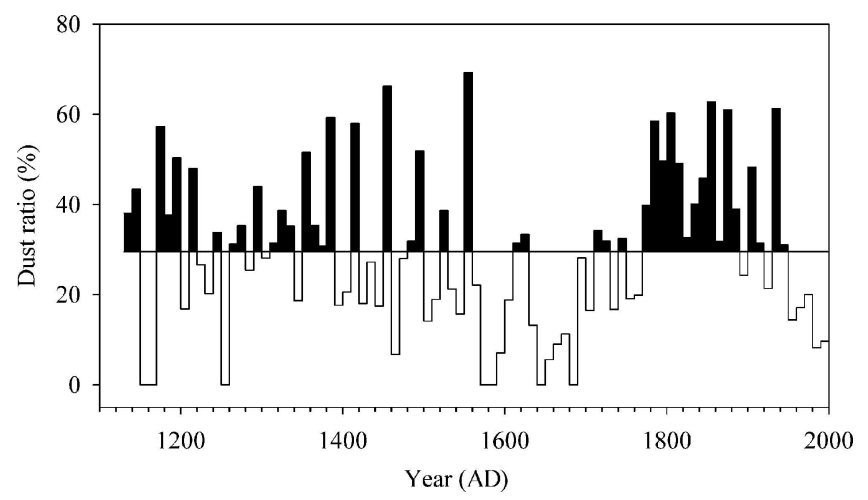

Fig. 4. Variations in dust ratio in the Malan ice core since the 1130 s. The histogram represents the decadal averages of the time series, and the horizontal line is the average value $(29.5 \%)$ over the entire period.

that the Malan ice core could preserve the information of past dust events. It is apparent that there is an abundance of visible yellow layers in the core, the thicknesses of which were measured for this study. To better understand the dust events recorded in the ice core, we collected data on such activity from meteorological stations in southern Xinjiang (He and others, 2003; S. Wang and others, 2003), and compared them with the ice-core record. With the time series of $\delta^{18} \mathrm{O}$ and dust events in the core, we can use statistical methods to construct the correlation between them.

\section{DUST RATIO AND DUST EVENT FREQUENCY}

Glacial dust layers can be formed by dust events and/or by the processes by which wind blows aerosols and/or debris from exposed hills surrounding a glacier onto its surface. For mountain glaciers with surfaces that are lower than the surrounding exposed hills, both processes can be relevant. However, for those glaciers with surfaces that are higher than the surrounding land, dust events are probably a more important factor for the formation of dust layers, especially those that are visible. The Malan ice-core drilling site is far from, and much higher than, the margins of the ice cap (see Fig. 1), so the formation of the visible yellow dust layers in the core should be attributed to dust events.

The positions of the dust layers with respect to the seasonal variations in $\delta^{18} \mathrm{O}$ (Fig. 2) indicate that most of the former appear in the spring. This suggests that dust events occur mainly during spring, which is consistent with observations for north China, including southern Xinjiang (Zhou, 2001; S. Wang and others, 2003). We can infer that dust layers in the Malan core are related to dust events, so we can use the former to reconstruct the record of the latter. The thicknesses of these layers vary at depth (Fig. 2), possibly because of variations in the DEF, accumulation rate and icelayer thinning. Just as concentrations of melt layers in polar ice cores are indicators of past summer climate (Herron and others, 1981; Koerner and Fisher, 1990), the concentrations of the dust layers in the Malan ice core have the potential to characterize past DEF. Hence, we suggest that the ratio of the dust layer thickness to the ice thickness, i.e. the dust ratio, in a given time period can be used as a proxy for DEF. 


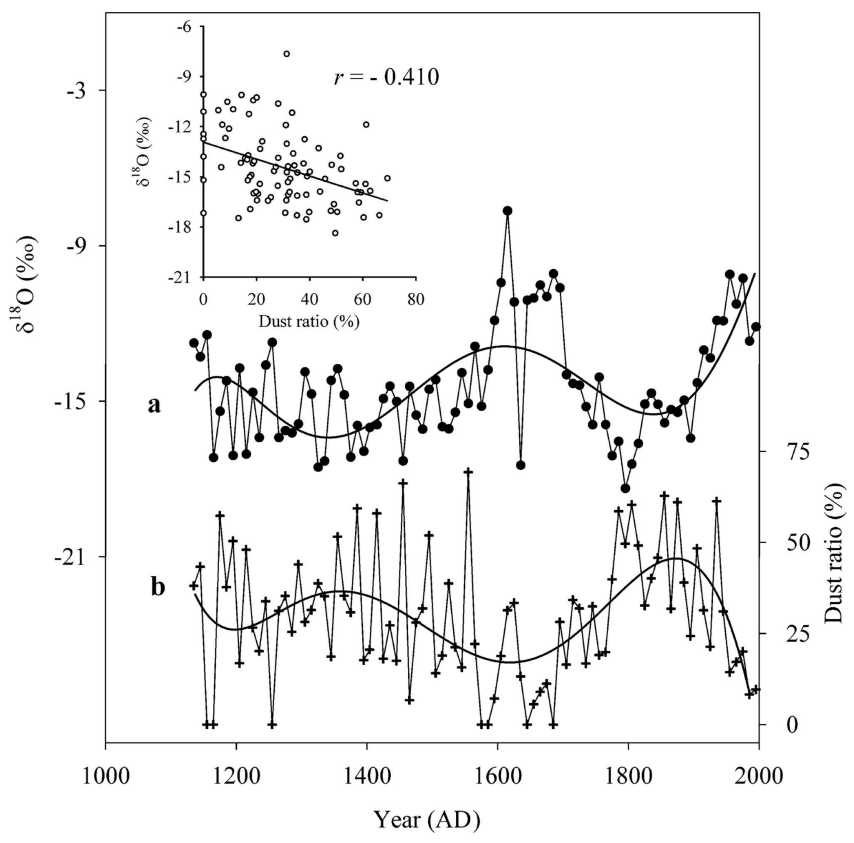

Fig. 5. Variations in $\delta^{18} \mathrm{O}$ (a) and dust ratio (b) in the Malan ice core since the 1130s. The curves with symbols represent the decadal averages, and the smooth curves are their sixth-order regressions. The insert illustrates the correlation between dust ratio and $\delta^{18} \mathrm{O}$.

Figure 3 illustrates the variations in dust ratio in the Malan ice core and the frequency of dust events that occur in the spring in southern Xinjiang during the past 50 years ( $\mathrm{He}$ and others, 2003). Their variations are obviously similar, and both display the same decreasing trend, which implies that the dust ratio can significantly reflect the DEF.

Based on the timescale of the Malan ice core, we reconstructed the variations in dust ratio since the 1130 s (Fig. 4). Over this time, the ratio varies from a maximum of $69.3 \%$ (during periods of active dust events) to a minimum of $0 \%$ (during calm periods), with the average ratio being $29.5 \%$. The longest active period lasted over one century, from the 1770s through the 1880s, and the longest calm period lasted 80 years, from the 1630 s through the $1700 \mathrm{~s}$. From Figure 4 , it can be seen that the general trend in the dust ratio has decreased during the most recent two centuries, implying that the DEF trend has also decreased.

\section{CORRELATION BETWEEN DUST EVENT FREQUENCY AND AIR TEMPERATURE}

A strong positive correlation was found between contemporaneous measurements of $\delta^{18} \mathrm{O}$ in precipitation samples and air temperatures from an array of meteorological stations over the northern Tibetan Plateau (Yao and others, 1996). This indicates that $\delta^{18} \mathrm{O}$ in ice cores from this region, such as those from the Malan ice cap, can be used as reasonable proxies for air temperature. Thus, we can investigate the correlation between DEF and air temperature based on the datasets of dust ratio and $\delta^{18} \mathrm{O}$ in this core.

Figure 5 shows the variations in decadal averages of dust ratios and $\delta^{18} \mathrm{O}$. The correlation coefficient between them is -0.410 , with a confidence level of $99.9 \%$. In order to investigate their relationships on different timescales, we

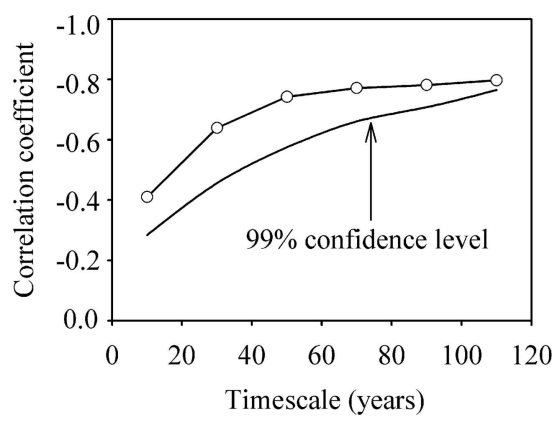

Fig. 6. Correlations between dust ratio and $\delta^{18} \mathrm{O}$ in the Malan ice core for different running averages.

calculated the correlation coefficients based on different running averages of the 10 year means of the two parameters, i.e. the three-point running averages comprise the 30 year timescales, the five-point running averages comprise the 50 year timescales, etc. Figure 6 indicates that the correlation between the dust ratio and the $\delta^{18} \mathrm{O}$ becomes more significant at lower-frequency timescales. At centennial-scale resolutions, the correlation coefficient reaches -0.797 , with a confidence level of $99 \%$.

To better understand the frequency of dust events under different climatic conditions, we first divided the dust ratio and $\delta^{18} \mathrm{O}$ into groups based on the different intervals of dust ratio, then calculated the means of the dust ratio and $\delta^{18} \mathrm{O}$ in each group and finally computed their correlation coefficients. These were found to be strongly negative (Table 1), implying that dust events occur more frequently in cold periods than in warm periods.

\section{DISCUSSION}

The correlation between dust events and climate revealed by the Malan ice-core record is consistent with results derived from other records. A study of Chinese historical documents illustrates that the 'dust rain' in eastern China occurred more frequently in cold weather (Zhang, 1982). Chinese loess studies also show that, in northern China, dust events have occurred more frequently and intensively in cold periods than in warm periods (Liu, 1985; Lu and Sun, 2000). However, it is also noted that ice-core records

Table 1. Correlation coefficients between dust ratio and $\delta^{18} \mathrm{O}$ in the Malan ice core when the original data were divided into groups on the basis of the different intervals of the dust ratio. Interval of dust ratio in the first column is an equal interval by which the range of the dust ratio record, $0-69.3 \%$, was divided into parts. In each part, there are a number of data of dust ratio and their corresponding data of $\delta^{18} \mathrm{O}$, which form a group. Procedure for calculating correlation coefficients is given in the text. The confidence levels of all the correlation coefficients are $99.5 \%$

Interval of dust ratio Number of groups Correlation coefficient

$\begin{array}{lrr}\text { Original data } & 87 & -0.410 \\ 3 \% & 23 & -0.775 \\ 5 \% & 14 & -0.853 \\ 7 \% & 10 & -0.926 \\ 10 \% & 7 & -0.941\end{array}$


and historical documents describe these relationships at high resolutions of $10^{1}-10^{2}$ years, while records from Chinese loess profiles are of much lower resolutions of $10^{3}-10^{4}$ years.

At present, the causes of dust storms that occur in northern China are not clear. Some studies have pointed out that natural factors have been largely responsible for their occurrence (Ye and others, 2000; Li and others, 2004), but others have considered human factors (Song, 2004; Wei and Zhang, 2004). All these conclusions were reached based on short-term observations. The Malan ice-core record provides long-term datasets, and indicates that there has been a strong negative correlation between the DEF and air temperature over the past nine centuries. This supports the hypothesis that natural forces might be the main control on the occurrence of dust events.

Recently, a study pointed out that dust cools the climate system (Kaufman and others, 2001). Our local results cannot be used as evidence that tropospheric dust loading forces climate cooling, even though we have demonstrated a significant negative correlation between the DEF and air temperature. However, the results presented here may suggest that dust loading could be a factor in a feedback mechanism that influences climate change, i.e. high dust loading in cold periods may reinforce climate cooling that is already underway.

\section{CONCLUSIONS}

Because dust events, i.e. dust storms, blowing sand and floating dust, influence not only climates but also inhabited environment, much attention has recently been paid to the study of these phenomena. In this paper, we extended the time series of dust ratios (a proxy for DEF) in the Malan ice core back to the early 12th century, and found that during this period dust events occurred most frequently in the 19th century. The Malan ice-core record also shows that there is a strong negative correlation between the DEF and air temperature over the past nine centuries, which suggests that climatic factors may be linked with the occurrence of dust events. This strong negative correlation could be explained by the following scenario: when climate cools, the westerlies are enhanced, which increases the frequency and magnitude of dust events, and sets up a feedback (Wang, 2005). Moreover, our results raise a question which should be studied in the future: has the atmospheric dust loading been decreasing as demonstrated for the Malan core site during the past two centuries? If so, temperature change resulting from the atmospheric dust burden must be estimated, so that the greenhouse temperature signal can be detected with greater confidence.

\section{ACKNOWLEDGEMENTS}

This research work is supported by the Centurial Program (2004401) and the Innovation Research Project (KZCX3-SW339-3) of the Chinese Academy of Sciences, the Chinese National Science Foundation (40525001, 40121101) and the National Basic Research Program of China (2005CB422003). We thank two anonymous reviewers for their helpful suggestions and comments which greatly improved this paper.

\section{REFERENCES}

Andreae, M.O. 1996. Raising dust in the greenhouse. Nature, 380(6573), 389-390.

Engelstaedter, S., K.E. Kohfeld, I. Tegen and S.P. Harrison. 2003. Controls of dust emissions by vegetation and topographic depressions: an evaluation using dust storm frequency data. Geophys. Res. Lett., 30(6), 1294. (10.1029/2002GL016471.)

He, Q., Q. Yang and H.J. Li. 2003. Variations of air temperature, precipitation and sand-dust weather in Xinjiang in past 40 years. J. Glaciol. Geocryol., 25(4), 423-427. [In Chinese with English abstract.]

Herron, M.M., S.L. Herron and C.C. Langway, Jr. 1981. Climatic signal of ice melt features in southern Greenland. Nature, 293(5831), 389-391.

Kaufman, Y.J., D. Tanré, O. Dubovik, A. Karnieli and L.A. Remer. 2001. Absorption of sunlight by dust as inferred from satellite and ground-based remote sensing. Geophys. Res. Lett., 28(8), 1479-1482.

Kaufman, Y.J., D. Tanré and O. Boucher. 2002. A satellite view of aerosols in the climate system. Nature, 419(6903), 215-223.

Koerner, R.M. and D.A. Fisher. 1990. A record of Holocene summer climate from a Canadian high-Arctic ice core. Nature, 343(6259), 630-631.

Li, D., T. Wang and H. Zhong. 2004. Climatic cause of sand-dust storm formation in northern China and its trend forecast. J. Desert Res., 24(3), 376-379. [In Chinese with English abstract.]

Liu, T. 1985. Loess and environment. Beijing, China Ocean Press. [In Chinese.]

Lu, H. and D. Sun. 2000. Pathways of dust input to the Chinese Loess Plateau during the last glacial-interglacial periods. Catena, 40(3), 251-261.

Martin, J.H. and 43 others. 1994. Testing the iron hypothesis in ecosystems of the equatorial Pacific Ocean. Nature, 371(6493), 123-129.

Prospero, J.M. and P.J. Lamb. 2003. African droughts and dust transport to the Caribbean: climate change implications. Science, 302(5647), 1024-1027.

Ramanathan, V., P.J. Crutzen, J.T. Kiehl and D. Rosenfeld. 2001. Aerosols, climate, and the hydrological cycle. Science, 294(5549), 2119-2124.

Ridgwell, A.J. 2002. Dust in the Earth system: the biogeochemical linking of land, air and sea. Philos. T. Roy. Soc, Ser. A, 360(1801), 2905-2924

Song, Z. 2004. Natural factors and human activities factors that induce sandy storm. J. China Agricult. Resources. Reg. Plan., 25(2), 5-8. [In Chinese with English abstract.]

Wang, N. 2005. Decrease trend of dust event frequency over the past 200 years recorded in the Malan ice core from the northern Tibetan Plateau. Chinese Sci. Bull., 50(24), 2866-2871.

Wang, N., L.G. Thompson, M.E. Davis, E. Mosley-Thompson, T. Yao and J. Pu. 2003a. Influence of variations in NAO and SO on air temperature over the northern Tibetan Plateau as recorded by $\delta^{18} \mathrm{O}$ in the Malan ice core. Geophys. Res. Lett., 30(22), 2167. (10.1029/2003GL018188.)

Wang, N., T. Yao, J. Pu, Y. Zhang, W. Sun and Y. Wang. 2003b. Variations in air temperature during the last 100 years revealed by $\delta^{18} \mathrm{O}$ in the Malan ice core from the Tibetan Plateau. Chinese Sci. Bull., 48(19), 2134-2138.

Wang, N., T. Yao, J. Pu, Y. Zhang and W. Sun. In press. Climatic and environmental changes over the last millennium recorded in the Malan ice core from the northern Tibetan Plateau. Sci. China D.

Wang, S., J. Wang, Z. Zhou, K. Shang, D. Yang and Z. Zhao. 2003. Regional characteristics of dust events in China. Acta Geogr. Sinica, 58(2), 193-200. [In Chinese with English abstract.]

Watson, A.J., D.C.E. Bakker, A.J. Ridgwell, P.W. Boyd and C.S. Law. 2000. Effect of iron supply on Southern Ocean $\mathrm{CO}_{2}$ uptake and implications for glacial atmospheric $\mathrm{CO}_{2}$. Nature, 497(6805), 730-733 
Wei, H. and H. Zhang. 2004. The relationships between the sandstorm and human factors. J. Arid Land Resources Environ. 18(4), 1-6. [In Chinese with English abstract.]

Yao, T., L.G. Thompson, E. Mosley-Thompson, Z. Yang, X. Zhang and P. Lin. 1996. Climatological significance of $\delta^{18} \mathrm{O}$ in north Tibetan ice cores. J. Geophys. Res., 101(D23), 29,531-29,538.

Ye, D.Z. and 7 others. 2000. Causes of sand-stormy weather in northern China and control measures. Acta Geogr. Sin., 55(5), 513521. [In Chinese with English abstract.]

Zhang, D. 1982. Anatomy of dust rain in history. Chinese Sci. Bull., 27(5), 294-297. [In Chinese.]

Zhou, Z. 2001. Blowing-sand and sandstorm in China in recent 45 years. Quat. Sci., 21(1), 9-17. [In Chinese with English abstract.] 